\title{
Effects of ball milling on microstructures and thermoelectric properties of higher manganese silicides
}

\author{
Xi Chen ${ }^{\mathrm{a}}$, Li Shi ${ }^{\mathrm{a}, \mathrm{b}, *}$, Jianshi Zhou ${ }^{\mathrm{a}, \mathrm{b}}$, and John B. Goodenough ${ }^{\mathrm{a}, \mathrm{b}}$ \\ ${ }^{a}$ Materials Science and Engineering Program, Texas Materials Institute, the University of Texas at Austin, \\ Austin, Texas, 78712, USA \\ ${ }^{b}$ Department of Mechanical Engineering, the University of Texas at Austin, Austin, Texas, 78712, USA
}

Bulk nanostructured higher manganese silicide (HMS) samples with different grain size are prepared by melting, subsequent ball milling (BM), and followed by spark

plasma sintering (SPS). The effects of BM time on the microstructures and thermoelectric properties of these samples are investigated. It is found that BM effectively reduces the grain size to about $90 \mathrm{~nm}$ in the sample after SPS, which leads to a decrease in both the thermal conductivity and electrical conductivity. By prolonging the BM time, MnSi and tungsten/carbon-rich impurity phases are formed due to the impact-induced

decomposition of HMS and contamination from the tungsten carbide jar and balls during the BM, respectively. These impurities result in a reduced Seebeck coefficient and increased thermal conductivity above room temperature. The measured size-dependent lattice thermal conductivities agree qualitatively with the reported calculation results based on a combined phonon and diffuson model. The size effects are found to be increasingly significant as temperature decreases. Because of the formation of the impurity phases and a relatively large grain size, the $Z T$ values are not improved in the ball-milled HMS samples. These findings suggest the need of alternative approaches for

\footnotetext{
* Corresponding author. Tel.: 512-471-3109.

E-mail address: lishi@mail.utexas.edu (Li Shi)
} 
the synthesis of pure HMS with further reduced grain size and controlled impurity doping in order to enhance the thermoelectric figure-of-merit of HMS via nanostructuring.

Keywords: nanostructured materials, thermoelectric, sintering, ball milling

\section{Introduction}

Owing to the increased demand for energy and the negative environmental consequence of energy generation from fossil fuels, thermoelectric (TE) materials, which can be used to convert waste heat into electricity, have received renewed attention in the past decades $[1,2]$. The performance of TE materials is related to the dimensionless figure-of-merit $Z T=S^{2} \sigma T /\left(\kappa_{\mathrm{E}}+\kappa_{\mathrm{L}}\right)$, where $S, \sigma, T, \kappa_{\mathrm{E}}$, and $\kappa_{\mathrm{L}}$ are the Seebeck coefficient, electrical conductivity, absolute temperature, electronic thermal conductivity, and lattice thermal conductivity, respectively. The numerator $S^{2} \sigma$ is called the power factor $(P F)$. Recently, $Z T$ improvement has been reported in some nanostructured TE materials $[3,4]$.

The $Z T$ of nanostructured materials can be enhanced only if grain boundary scattering can result in a larger reduction in the lattice thermal conductivity than in the power factor. It has been reported that this approach is effective in several TE materials such as $\mathrm{AgPb}_{\mathrm{m}} \mathrm{SbTe}_{2+\mathrm{m}}[5], \mathrm{Bi}_{2} \mathrm{Te}_{3}$-based [6, 7], and $\mathrm{Si}_{80} \mathrm{Ge}_{20}[8,9]$ bulk nanostructured materials.

Higher manganese silicides (HMS) with composition of $\mathrm{MnSi}_{\sim 1.74}$ are regarded as attractive $p$-type TE materials owing to the abundance of the constituent elements in the earth crust, environmental friendliness and good chemical stability at high temperatures. The crystal structure of HMS belongs to the Nowotny chimney ladder (NCL) phases, which are characterized by two interpenetrating sublattices with the tetragonal Mn 
sublattice forming chimneys and the helical Si sublattice forming ladders along the $c$ axis. HMS single crystals prepared by the Bridgman method or Czochralski method possess anisotropic transport properties, which are related to the complex NCL structure and the layers of secondary MnSi phase precipitating perpendicular to the $c$ axis [10]. For example, the $\kappa_{\mathrm{L}}$ along the $c$ axis is approximately half of that along the $a$ axis at room temperature. Polycrystalline HMS samples are usually prepared by solid-state reaction or melting, and show nearly isotropic transport properties [11, 12].

The maximum $Z T$ of pure HMS has been reported to be about 0.4 at $800 \mathrm{~K}$ [11-13], which is still not sufficient for efficient thermoelectric conversion. In order to improve the $Z T$ of HMS, a number of works have been focused on optimization of TE properties by chemical doping or substitution $[11,12,14-22]$. For example, $\mathrm{Re}, \mathrm{Cr}, \mathrm{Ge}$, and $\mathrm{Al}$ dopants have been employed to tune the transport properties of HMS. These approaches have resulted in the enhancement of the maximum $Z T$ up to $0.6-0.7$ at about $800 \mathrm{~K}$. Recently, the effects of nanostructuring on HMS [23-34] have been investigated in an attempt to reduce the lattice thermal conductivity to enhance the $Z T$ values. In one theoretical analysis based on a semi-classical two-band model and Debye approximation for calculating charge and phonon transport, respectively, it was estimated that the ZT of HMS can be enhanced somewhat by reducing the grain size to about $10 \mathrm{~nm}$ [27]. Recently, the full phonon dispersion of HMS crystals has been obtained through first principle calculation and inelastic neutron scattering measurements [35]. The obtained phonon dispersion has been used to establish a thermal conductivity model where the numerous optical vibration modes are treated as diffusons. This new model suggests that a glass-like thermal conductivity can be obtained in nanostructured HMS with the grain 
size reduced to the $10 \mathrm{~nm}$ level, which is still large compared to the previously estimated charge mean free path of 1-2 nm in HMS crystals [27]. Therefore, the impact on the power factor is not expected to be large. However, there is a lack of experimental results to verify whether the predicted size effects on the thermoelectric properties of nanostructured HMS can be achieved in experiments.

Here we report the results from an experimental study of the effects of ball milling (BM) time on the microstructures and thermoelectric transport properties of HMS samples, which were prepared by melting, subsequent BM, and followed by spark plasma sintering (SPS). We found that the grain size of HMS can be reduced to the $500-90 \mathrm{~nm}$ range without noticeable secondary phase in the as-synthesized nanostructured HMS samples. However, further increasing BM time leads to the formation of $\mathrm{MnSi}$ and tungsten/carbon-rich phases resulting from the decomposition of HMS and the contamination of tungsten carbide (WC) jars and balls, respectively. Moreover, not only the $\kappa_{\mathrm{L}}$ but also the $\sigma$ and $P F$ decrease with increasing BM time because of the increasing impurity concentrations and also likely defects. As a result, the $Z T$ of HMS is not improved by BM. In addition, the measured grain size dependence of $\kappa_{\mathrm{L}}$ is used to verify the recent theoretical calculation [35] based on the phonon dispersion and a combined phonon and diffuson model. These results suggest the need of further reducing the grain size to $\sim 10 \mathrm{~nm}$ while maintaining the phase purity in order to obtain enhanced $Z T$ in nanostructured HMS samples. 


\section{Materials and methods}

\subsection{Preparation of bulk nanostructured HMS}

The samples were synthesized in three steps, i.e. melting, BM, and SPS. The starting materials, Mn (purity, 99.95\%) and Si (purity, 99.999\%) powders, were purchased from Alfa Aesar. The powders with nominal chemical composition of $\mathrm{MnSi}_{1.78}$ were mixed and sealed in a vacuumed quartz tube, and heat-treated in a furnace at $900{ }^{\circ} \mathrm{C}$ for $24 \mathrm{~h}$; they were then melted at $1300{ }^{\circ} \mathrm{C}$ for $10 \mathrm{~h}$ and cooled by turning off the power of furnace. Subsequently, the obtained ingot was loaded into a tungsten-carbide jar and ball-milled in argon by using a SPEX 8000M Mixer/Mill (SPEX SamplePrep). The grain sizes were controlled by means of changing the BM time, which was from 2 to 54 hours. Finally, the ball-milled powders were consolidated into dense pellets at $950-1000{ }^{\circ} \mathrm{C}$ for 5 minutes under $60 \mathrm{MPa}$ by using SPS (Thermal Technology LLC). The bulk samples obtained by applying SPS to powders ball-milled for $2 \mathrm{~h}, 6 \mathrm{~h}, 18 \mathrm{~h}$ and $54 \mathrm{~h}$ are denoted as BM2h, BM6h, BM18h, and BM54h, respectively.

\subsection{Characterization of HMS}

The phase purity and crystal structure of the products were studied by powder X-ray diffraction (XRD) using a Phillip X'pert diffractometer with $\mathrm{Cu} \mathrm{K}_{\alpha}$ radiation. The morphology and compositions of the samples were analyzed by using a Quanta 650 environmental scanning electron microscope (SEM) with an energy-dispersive X-ray (EDX) spectrometer. The electrical conductivity $(\sigma)$ was measured in the temperature range between $10 \mathrm{~K}$ and $823 \mathrm{~K}$ with a four-probe method. The Seebeck coefficient $(S)$ was measured in the temperature range $80-823 \mathrm{~K}$ with home-made setups. The thermal diffusivity $(\lambda)$ was measured with the laser flash diffusivity method in a Netzsch LFA 
457. The specific heat $\left(\mathrm{C}_{\mathrm{p}}\right)$ was obtained by a differential scanning calorimetry (DSC) system (Netzsch DSC 404). The density of the pellets ( $\rho$ ) was determined by the Archimedes' method. The thermal conductivity from $323 \mathrm{~K}$ to $873 \mathrm{~K}$ was calculated as $\kappa=\lambda \mathrm{C}_{\mathrm{p}} \rho$. The low-temperature thermal conductivity was measured by a steady-state method from $30 \mathrm{~K}$ to $300 \mathrm{~K}$. All three transport properties were measured along the direction parallel to the SPS pressing force. The Hall coefficient $\left(R_{\mathrm{H}}\right)$ at low temperature was determined by using a Physical Properties Measurement System (PPMS, Quantum Design) with the magnetic field sweeping between $\pm 2 \mathrm{~T}$. The carrier concentration $\left(p_{\mathrm{H}}\right)$ and mobility $\left(\mu_{\mathrm{H}}\right)$ were calculated as $p_{\mathrm{H}}=1 /\left(e R_{\mathrm{H}}\right)$ and $\mu_{\mathrm{H}}=\sigma /\left(e p_{\mathrm{H}}\right)$, where $e$ is the electron charge.

\section{Results and discussion}

\subsection{Phase and microstructures}

The powder XRD patterns of products after melting, BM, and SPS are shown in Fig. 1. It can be seen that HMS was formed after melting without detectable secondary phases. After BM for $18 \mathrm{~h}$, the XRD peaks become significantly broader without the presence of other impurity peaks. However, distinct MnSi peaks were observed in the sample ball-milled for $54 \mathrm{~h}$. Zhou et al. [36] reported that HMS decomposed into MnSi in the $\mathrm{BM}$ process according to $\mathrm{HMS} \rightarrow \mathrm{MnSi}+\mathrm{Si}$. Additional $\mathrm{Si}$ could be oxidized into amorphous $\mathrm{SiO}_{2}$. Another possible reason for the formation of $\mathrm{MnSi}$ could be the phase transition of HMS during BM. It has been reported by Allam et al. $[37,38]$ that one phase

of HMS can be transferred to another at high temperature. The sample after melting could be a mixture of several phases of HMS [39], and their Si ratio is slightly different. One of 
them with lower Si ratio may be transferred to another one with higher Si ratio plus $\mathrm{MnSi}$ during BM process. A small peak from the WC phase was found in the powders ballmilled for $54 \mathrm{~h}$ due to the abrasion of the milling tools. After SPS, a minor $\mathrm{WSi}_{2}$ phase was observed in the BM54h sample. The average grain size after BM was obtained by analyzing the XRD pattern with the Scherrer equation [40]. The grain size is about $40 \mathrm{~nm}$ for the samples ball-milled for $18 \mathrm{~h}$ and $54 \mathrm{~h}$. This observation indicates that increasing the BM time does not further refine the grain size, but leads to the decomposition of HMS. The grain sizes after SPS are increased to $90 \pm 20$ and $143 \pm 83 \mathrm{~nm}$ for the sample ball-milled for $18 \mathrm{~h}$ and $54 \mathrm{~h}$, respectively.

Figure 2 shows the SEM images of the fracture surface of the samples after SPS with different BM times. The grain size is reduced with increasing BM time. The average grain sizes $\left(\mathrm{L}_{\mathrm{d}}\right)$ estimated from the SEM images are about 500, 320, 90, and $130 \mathrm{~nm}$ for the bulk sample obtained by applying SPS to precursor powders ball-milled for 2, 6, 18, and $54 \mathrm{~h}$, respectively. The slightly larger grain size of the BM54 h sample can be attributed to a slightly higher temperature used during SPS for this sample, as shown in Table 1. It should be noted that some grains shown in SEM may be agglomerates of smaller crystallites. Nevertheless, the SEM results for the BM18h and BM54h samples are consistent with the calculated crystallite size based on the XRD results. Figure 3(a) shows a secondary phase of about $40 \mu \mathrm{m}$ found in the BM54h sample. The magnified SEM image (Figure 3(b)) indicates that the secondary phase is a cluster made of many flower-like phases. Some individual secondary phases were also observed as bright inclusions in the backscattered electron images (Figure 3(c) and (d)). The elemental mapping analysis indicates that the bright inclusion consists of a carbon-rich core and a 
tungsten, silicon-rich shell. The formation of the secondary phase could be attributed to the reaction of WC introduced from the WC jar/balls with HMS during SPS. It should be noted that the MnSi phase was not observed by SEM, which may be due to the homogeneous mixing of HMS and MnSi.

\subsection{Electronic transport properties}

The temperature dependence of Hall carrier density $\left(p_{\mathrm{H}}\right)$ and mobility $\left(\mu_{\mathrm{H}}\right)$ for the HMS samples are plotted in Fig. 4. For the three samples ball-milled for 2 h, 6 h, and 18 $\mathrm{h}$, the room-temperature $p_{\mathrm{H}}$ is similar and close to $1.3 \times 10^{21} \mathrm{~cm}^{-3}$. Furthermore, the $p_{\mathrm{H}}$ values are almost constant with temperature, which is typical for degenerate semiconductors. In addition, the $\mu_{\mathrm{H}}$ decreases with decreasing grain size for these three samples. In comparison, the BM54h sample shows the highest $p_{\mathrm{H}}$ and lowest $\mu_{\mathrm{H}}$ at room temperature, as is shown in Table 1. This result could be attributed to the formation of MnSi and W/C-rich phases. The lower $\mu_{\mathrm{H}}$ and higher $p_{\mathrm{H}}$ were also observed by Itoh et al. in a sample with coexistence of HMS and MnSi prepared by mechanical alloying and SPS [41].

The temperature dependence of $\mu_{\mathrm{H}}$ can be used to determine the dominant carrier scattering mechanism. As shown in Fig. 4b, the mobility varies approximately as $T^{-3 / 2}$ for all samples above $100 \mathrm{~K}$, which indicates that acoustic phonon scattering [42] is the dominant scattering mechanism. For the BM18h sample, the mobility follows a

relationship of $\mu_{\mathrm{H}} \propto T^{-1 / 2}$ below $100 \mathrm{~K}$, which reveals the effect of increased grain boundary scattering [43]. 
The temperature-dependent thermoelectric transport properties of four samples are depicted in Fig. 5. The $S$ of the BM54h sample was reduced significantly as compared to other samples, which is mainly caused by the formation of metallic MnSi [14]. This reduction of $S$ was also observed in the HMS samples containing large amount of $\mathrm{MnSi}$ prepared by mechanical alloying followed by hot-pressing or SPS [44-47]. The $\sigma$ below $300 \mathrm{~K}$ decreases monotonically with increasing BM time due to reduced grain size and possibly increased point-defect concentration. However, the BM18h and BM54h samples exhibit higher $\sigma$ values than that of the BM6h sample above $700 \mathrm{~K}$, which could be related to the formation of secondary MnSi phase. As a consequence, the $P F$ is reduced by BM. The peak $P F$ is decreased from $1.3 \times 10^{-3} \mathrm{~W} \mathrm{~m}^{-1} \mathrm{~K}^{-2}$ for the BM2h sample to $0.4 \times 10^{-3} \mathrm{~W} \mathrm{~m}^{-1} \mathrm{~K}^{-2}$ for the BM54h sample. It should be noted that the formation of MnSi during BM process was observed in pure HMS as starting material. It can be of interest to study whether doping can prevent from the formation of $\mathrm{MnSi}$ and maintain good electrical properties.

\subsection{Thermal conductivity and $Z T$}

The temperature dependence of total and lattice thermal conductivities is given in Fig. 6. It is clear that the reduction of the grain size leads to lower $\kappa$ values at temperatures below $700 \mathrm{~K}$. The $\kappa_{\mathrm{L}}$ is calculated by subtracting the $\kappa_{\mathrm{E}}$ from the total thermal conductivity according to $\kappa_{\mathrm{E}}=L \sigma T$, where the Lorenz number $(L)$ is calculated as [48]

$$
L=\frac{k_{\mathrm{B}}{ }^{2}}{e^{2}} \frac{3 F_{0}(\eta) F_{2}(\eta)-4 F_{1}(\eta)^{2}}{F_{0}(\eta)^{2}}
$$


and

$$
F_{i}(\eta)=\int_{0}^{\infty} x^{i}\left(e^{x-\eta}+1\right)^{-1} d x
$$

where $k_{\mathrm{B}}$ is the Boltzmann constant, and the Fermi integral, $F_{i}(\eta)$, is a function of reduced chemical potential $\eta$. The bipolar contribution to $\kappa$ has not been included in this calculation since it is small below $800 \mathrm{~K}$ according a recent analysis [17]. The $\kappa_{\mathrm{L}}$ at $30 \mathrm{~K}$ is significantly reduced from $\sim 7.8 \mathrm{~W} \mathrm{~m}^{-1} \mathrm{~K}^{-1}$ for the $\mathrm{BM} 2 \mathrm{~h}$ sample to $\sim 1.6 \mathrm{~W} \mathrm{~m}^{-1} \mathrm{~K}^{-1}$ for the BM18h sample. However, this reduction is not remarkable at high temperature, which is from $\sim 2.3 \mathrm{~W} \mathrm{~m}^{-1} \mathrm{~K}^{-1}$ for the $\mathrm{BM} 2 \mathrm{~h}$ sample to $\sim 2.0 \mathrm{~W} \mathrm{~m}^{-1} \mathrm{~K}^{-1}$ for the $\mathrm{BM} 18 \mathrm{~h}$ sample at $637 \mathrm{~K}$. Likely due to larger grain sizes and the presence of MnSi and other impurity phases that can possess higher thermal conductivity than that of HMS, the BM54h sample exhibits higher $\kappa_{\mathrm{L}}$ than the BM18h sample.

In order to understand better phonon transport in nanostructured HMS, we have compared the grain size dependence of the $\kappa_{\mathrm{L}}$ for the BM2h, BM6h and BM18h samples with the calculated $\kappa_{\mathrm{L}}$ along the $a$ and $c$ axes with different boundary scattering MFPs [35], as shown in Fig. 7. The $\kappa_{\mathrm{L}}$ calculation is based on a combined phonon and diffuson model as discussed in a recent report [35]. The calculation results indicate that the $\kappa_{\mathrm{L}}$ can be reduced significantly when the grain size is reduced to $10 \mathrm{~nm}$. The experimental data follow the trend predicted suggested by the model prediction.

Figure 8 shows the dimensionless figure-of-merit ZT of the HMS samples. Although the $\kappa_{\mathrm{L}}$ is suppressed by long BM time, the $P F$ is also reduced due to the partial decomposition of the HMS phase. As a result, the BM process does not improve the ZT. The peak $Z T$ is 0.39 for the $\mathrm{BM} 2 \mathrm{~h}$ sample at $770 \mathrm{~K}$, which is comparable to the HMS sample without nanostructuring [49], but is reduced to 0.1 for the BM54h sample because 
of the considerably reduced power factor as a result of the increased impurity phase as well as defect concentrations. In addition, while the $\kappa_{\mathrm{L}}$ could be suppressed significantly above $300 \mathrm{~K}$ if the grain size reaches $10 \mathrm{~nm}$ according to the theoretical calculation [35], the relatively large grain size of more than $90 \mathrm{~nm}$ in these samples limits the extent of thermal conductivity reduction.

\section{Conclusions}

Bulk nanostructured HMS samples have been prepared by melting, subsequent BM and followed by SPS. The experimental results have revealed the effects of ball milling on the phase, microstructures and thermoelectric transport properties of bulk HMS samples. A prolonged BM time has been found to lead to the formation of MnSi and contamination of WC jars/balls, which are detrimental to the TE performance. Both $\kappa_{\mathrm{L}}$ and $\sigma$ decrease with increasing BM time. In addition, the grain-size effects on the thermal conductivity are more significant at low temperatures below $300 \mathrm{~K}$. The grain size dependence of lattice thermal conductivity agrees qualitatively with a recent theoretical calculation. Because the formation of impurity phases and also possibly an increasing point-defects concentration reduce the $P F$ more than the suppression in the $\kappa_{\mathrm{L}}$, the $Z T$ is not improved by increasing BM time for the samples prepared in this work. Thus, alternative approaches, such as the bottom-up approach [26], should be explored to synthesize HMS bulk samples with further reduced grain size toward 10-20 nm with controlled impurity concentrations.

\section{Acknowledgments}


The work is supported by NSF/DOE Joint Thermoelectric Partnership (NSF award number: CBET-1048767). The SPS processing and Hall measurements at the University of Texas at Austin were conducted with instruments acquired with the support of NSF award number DMR-1229131 and NSF award number DMR-1122603.

\section{References}

[1] F.J. DiSalvo, Science, 285 (1999) 703-706.

[2] B.C. Sales, Science, 295 (2002) 1248-1249.

[3] M.S. Dresselhaus, G. Chen, M.Y. Tang, R. Yang, H. Lee, D. Wang, Z. Ren, J.-P. Fleurial, P. Gogna, Adv. Mater., 19 (2007) 1043-1053.

[4] C.J. Vineis, A. Shakouri, A. Majumdar, M.G. Kanatzidis, Adv. Mater., 22 (2010) 3970-3980.

[5] K.F. Hsu, S. Loo, F. Guo, W. Chen, J.S. Dyck, C. Uher, T. Hogan, E.K. Polychroniadis, M.G. Kanatzidis, Science, 303 (2004) 818-821.

[6] X.B. Zhao, X.H. Ji, Y.H. Zhang, T.J. Zhu, J.P. Tu, X.B. Zhang, Appl. Phys. Lett., 86 (2005) 062111.

[7] B. Poudel, Q. Hao, Y. Ma, Y.C. Lan, A. Minnich, B. Yu, X.A. Yan, D.Z. Wang, A. Muto, D. Vashaee, X.Y. Chen, J.M. Liu, M.S. Dresselhaus, G. Chen, Z.F. Ren, Science, 320 (2008) 634-638.

[8] G. Joshi, H. Lee, Y.C. Lan, X.W. Wang, G.H. Zhu, D.Z. Wang, R.W. Gould, D.C. Cuff, M.Y. Tang, M.S. Dresselhaus, G. Chen, Z.F. Ren, Nano Lett., 8 (2008) 4670-4674.

[9] S.K. Bux, R.G. Blair, P.K. Gogna, H. Lee, G. Chen, M.S. Dresselhaus, R.B. Kaner, J.P. Fleurial, Adv. Funct. Mater., 19 (2009) 2445-2452.

[10] M.I. Fedorov, V.K. Zaitsev, in: D.M. Rowe (Ed.), Thermoelectrics Handbook: Macro to Nano, Taylor \& Francis Group, Boca Raton, 2006, pp. 1 - 17 (chapter 31).

[11] A.J. Zhou, T.J. Zhu, X.B. Zhao, S.H. Yang, T. Dasgupta, C. Stiewe, R. Hassdorf, E. Mueller, J. Electron. Mater., 39 (2010) 2002-2007.

[12] W.H. Luo, H. Li, F. Fu, W. Hao, X.F. Tang, J. Electron. Mater., 40 (2011) 12331237.

[13] X. Shi, X. Shi, Y. Li, Y. He, L. Chen, Q. Li, J. Appl. Phys., 116 (2014) 245104.

[14] I. Aoyama, M.I. Fedorov, V.K. Zaitsev, F.Y. Solomkin, I.S. Eremin, A.Y.

Samunin, M. Mukoujima, S. Sano, T. Tsuji, Jpn. J. Appl. Phys., 44 (2005) 8562-8570.

[15] I. Aoyama, H. Kaibe, L. Rauscher, T. Kanda, M. Mukoujima, S. Sano, T. Tsuji, Jpn. J. Appl. Phys., 44 (2005) 4275-4281.

[16] V. Ponnambalam, D.T. Morelli, J. Electron. Mater., 41 (2012) 1389-1394.

[17] X. Chen, A. Weathers, D. Salta, L.B. Zhang, J.S. Zhou, J.B. Goodenough, L. Shi, J. Appl. Phys., 114 (2013).

[18] X. Chen, S.N. Girard, F. Meng, E. Lara-Curzio, S. Jin, J.B. Goodenough, J. Zhou, L. Shi, Adv. Energy Mater., 4 (2014) 1400452. 
[19] N.L. Okamoto, T. Koyama, K. Kishida, K. Tanaka, H. Inui, Acta Mater., 57 (2009) 5036-5045.

[20] Y. Kikuchi, Y. Miyazaki, Y. Saito, K. Hayashi, K. Yubuta, T. Kajitani, Jpn. J. Appl. Phys., 51 (2012) 085801.

[21] Y. Sadia, N. Madar, I. Kaler, Y. Gelbstein, J. Electron. Mater., (2014) DOI: 10.1007/s11664-014-3500-z.

[22] A. Allam, P. Boulet, M.C. Record, J. Alloy. Compd., 584 (2014) 279-288.

[23] A.J. Zhou, X.B. Zhao, T.J. Zhu, Y.Q. Cao, C. Stiewe, R. Hassdorf, E. Mueller, J. Electron. Mater., 38 (2009) 1072-1077.

[24] W.H. Luo, H. Li, Y.G. Yan, Z.B. Lin, X.F. Tang, Q.J. Zhang, C. Uher, Intermetallics, 19 (2011) 404-408.

[25] A. Pokhrel, Z.P. Degregorio, J.M. Higgins, S.N. Girard, S. Jin, Chem. Mater., 25 (2013) 632-638.

[26] J.M. Higgins, A.L. Schmitt, I.A. Guzei, S. Jin, J. Am. Chem. Soc., 130 (2008) 16086-16094.

[27] P. Norouzzadeh, Z. Zamanipour, J.S. Krasinski, D. Vashaee, J. Appl. Phys., 112 (2012) 124308.

[28] Y. Sadia, Y. Gelbstein, J. Electron. Mater., 41 (2012) 1504-1508.

[29] D.Y.N. Truong, H. Kleinke, F. Gascoin, Dalton. Trans., 43 (2014) 15092-15097.

[30] M. Saleemi, A. Famengo, S. Fiameni, S. Boldrini, S. Battiston, M. Johnsson, M. Muhammed, M.S. Toprak, J. Alloy. Compd., 619 (2015) 31-37.

[31] X. Chen, A. Weathers, A. Moore, J. Zhou, L. Shi, J. Electron. Mater., 41 (2012) 1564-1572.

[32] Z. Zamanipour, X.H. Shi, M. Mozafari, J.S. Krasinski, L. Tayebi, D. Vashaee, Ceram. Int., 39 (2013) 2353-2358.

[33] Y. Gelbstein, J. Tunbridge, R. Dixon, M.J. Reece, H.P. Ning, R. Gilchrist, R. Summers, I. Agote, M.A. Lagos, K. Simpson, C. Rouaud, P. Feulner, S. Rivera, R. Torrecillas, M. Husband, J. Crossley, I. Robinson, J. Electron. Mater., 43 (2014) 17031711.

[34] G. Bernard-Granger, M. Soulier, H. Ihou-Mouko, C. Navone, M. Boidot, J. Leforestier, J. Simon, J. Alloy. Compd., 618 (2015) 403-412.

[35] X. Chen, A. Weathers, J. Carrete, S. Mukhopadhyay, O. Delaire, D.A. Stewart, N. Mingo, S.N. Girard, J. Ma, D.L. Abernathy, J.Q. Yan, R. Sheshka, D.P. Sellan, F. Meng, S. Jin, J.S. Zhou, L. Shi, Nat. Commun. (2015) DOI: 10.1038/ncomms7723.

[36] A.J. Zhou, X.B. Zhao, T.J. Zhu, T. Dasgupta, C. Stiewe, R. Hassdorf, E. Mueller, Intermetallics, 18 (2010) 2051-2056.

[37] A. Allen, C.A. Nunes, J. Zalesak, M.-C. Record, J. Alloy. Compd., 512 (2012) 278-281.

[38] A. Allen, P. Boulet, C.A. Nunes, J. Sopousek, P. Broz, M.-C. Record, J. Alloy. Compd., 551 (2013) 30-36.

[39] R. De Ridder, S. Amelinckx, Mater. Res. Bull. 6(1971) 1223-1234.

[40] J.G. Cheng, J.S. Zhou, J.B. Goodenough, Phys. Rev. B, 82 (2010) 132103.

[41] T. Itoh, M. Yamada, J. Electron. Mater., 38 (2009) 925-929.

[42] J. Bardeen, W. Shockley, Phys. Rev., 80 (1950) 72-80.

[43] J. de Boor, T. Dasgupta, H. Kolb, C. Compere, K. Kelm, E. Mueller, Acta Mater., 77 (2014) 68-75. 
[44] M. Umemoto, Z.G. Liu, R. Omatsuzawa, K. Tsuchiya, Mater. Sci. Forum, 343-3, (2000) 918-923.

[45] Y. Sadia, L. Dinnerman, Y. Gelbstein, J. Electron. Mater., 42 (2013) 1926-1931.

[46] Y.G. Lee, M.K. Choi, I.H. Kim, S.C. Ur, J. Ceram. Process Res., 13 (2012) 816-

819.

[47] D.K. Shin, K.W. Jang, S.C. Ur, I.H. Kim, J. Electron. Mater., 42 (2013) 17561761.

[48] X. Liu, T. Zhu, H. Wang, L. Hu, H. Xie, G. Jiang, G.J. Snyder, X. Zhao, Adv. Energy Mater., 3 (2013) 1238-1244.

[49] V. Ponnambalam, D.T. Morelli, S. Bhattacharya, T.M. Tritt, J. Alloy. Compd., 580 (2013) 598-603. 


\section{Figures:}

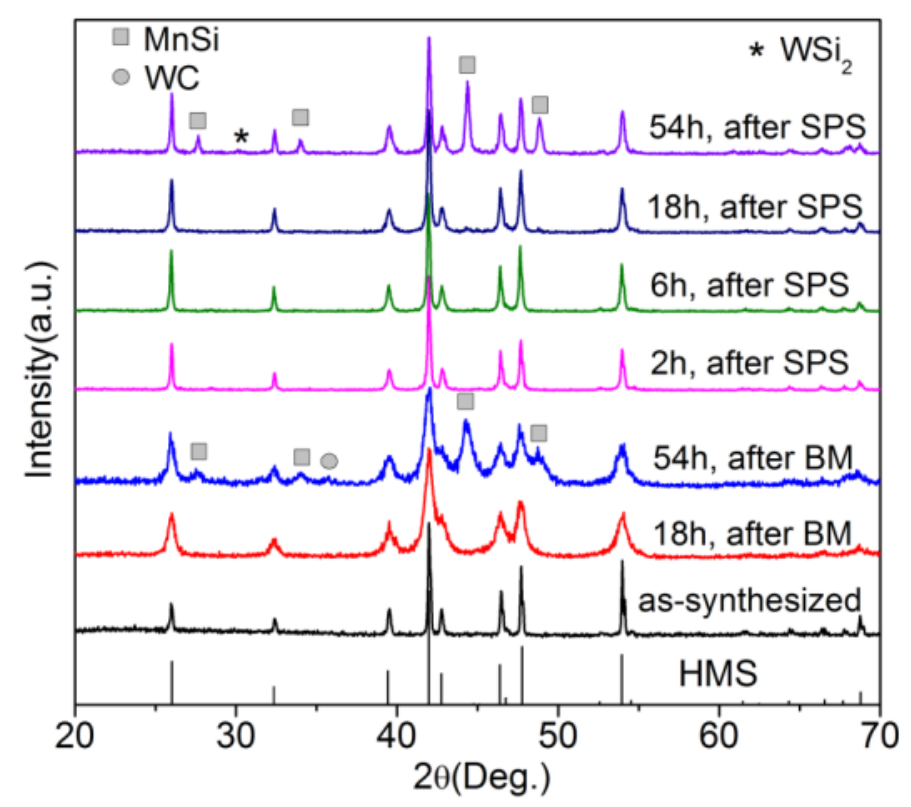

Fig. 1. XRD patterns of various HMS samples after melting, BM and SPS, respectively, with the $\mathrm{BM}$ time indicated as the number in the legend for each data. 

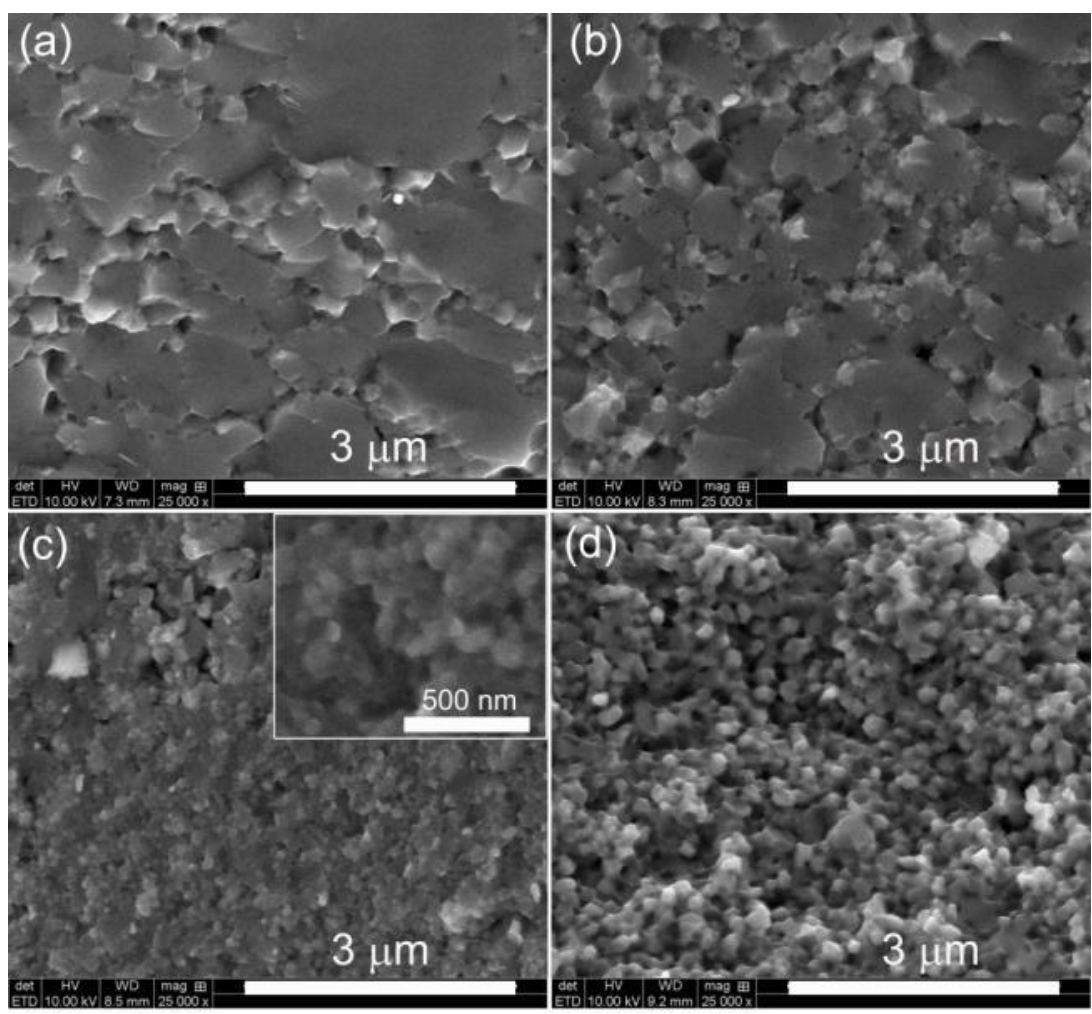

Fig. 2. SEM images of the fracture surface of various bulk HMS samples obtained by applying SPS to powders ball-milled for (a) $2 \mathrm{~h}$, (b) $6 \mathrm{~h}$, (c) $18 \mathrm{~h}$ and (d) $54 \mathrm{~h}$. The inset of (c) is the magnified SEM image. 

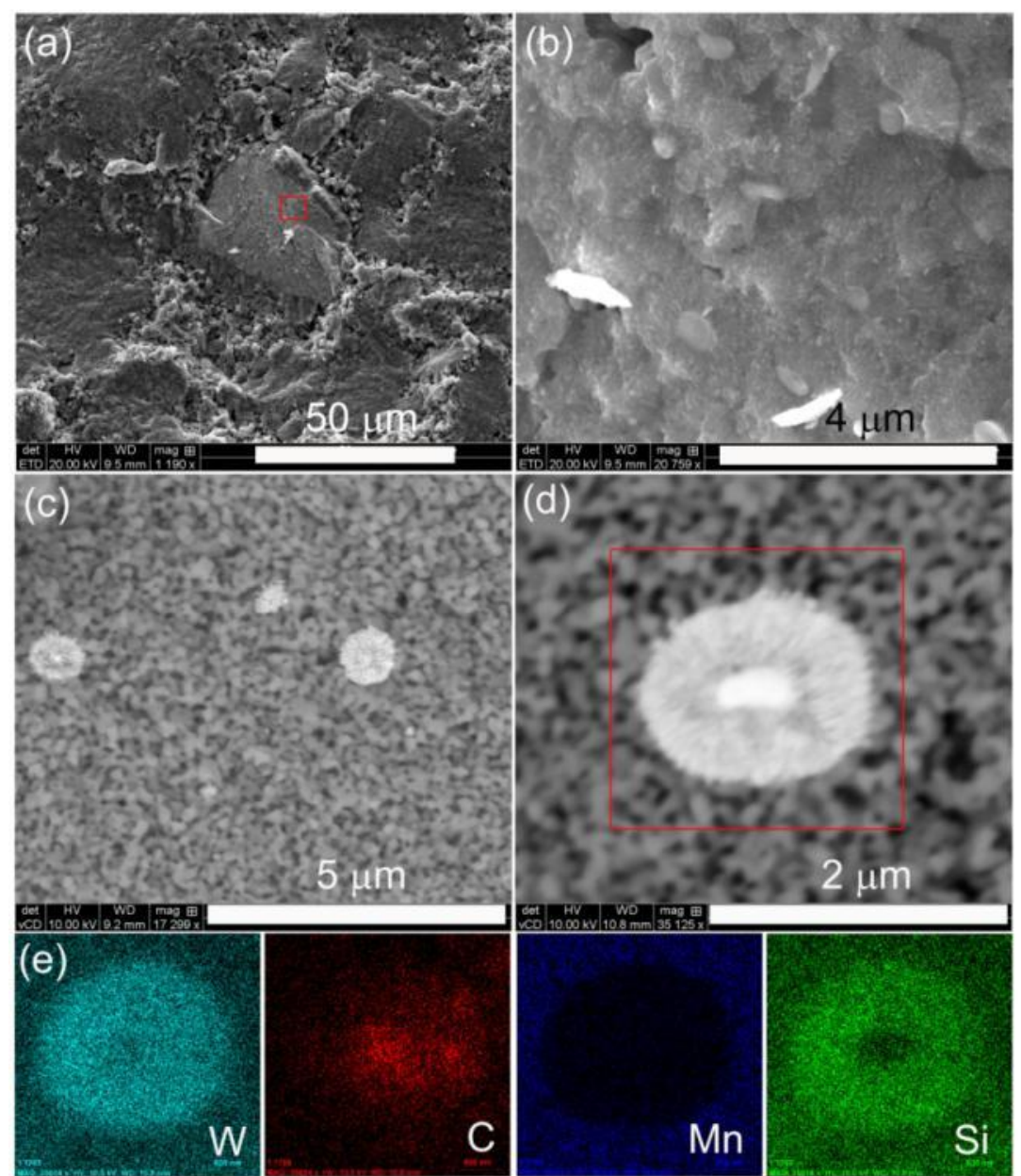

Fig. 3. (a) SEM image of the fracture surface of the BM54h sample. (b) High-resolution SEM image of the area marked by the red square in (a). (c), (d) Backscattered electron images of the fracture surface of the BM54h sample. (e) Elemental maps of the secondary phase in (d). 

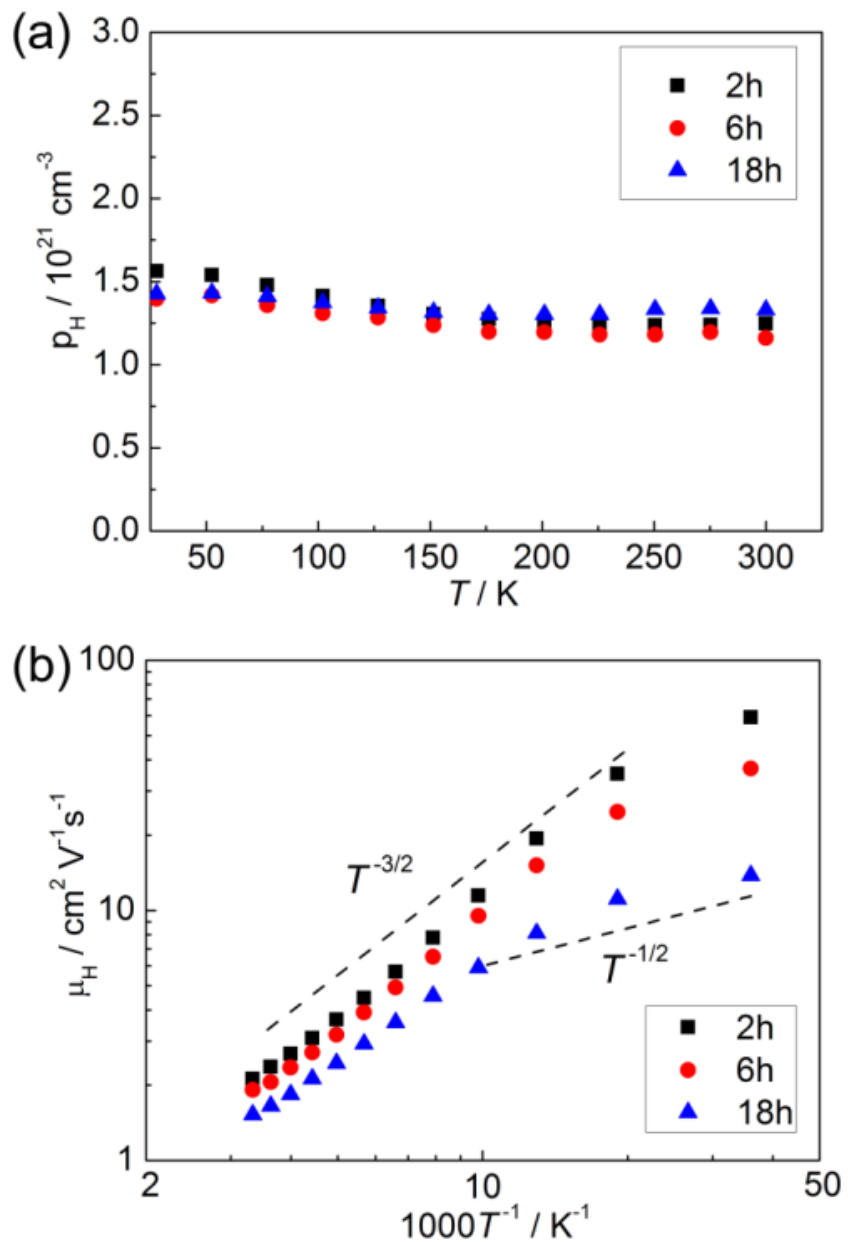

Fig. 4. (a) Hall carrier density and (b) mobility of the bulk HMS samples with different ballmilling times of 2,6 , and $18 \mathrm{~h}$. The uncertainty of carrier concentration and mobility are $6 \%$ and $8 \%$, respectively. 

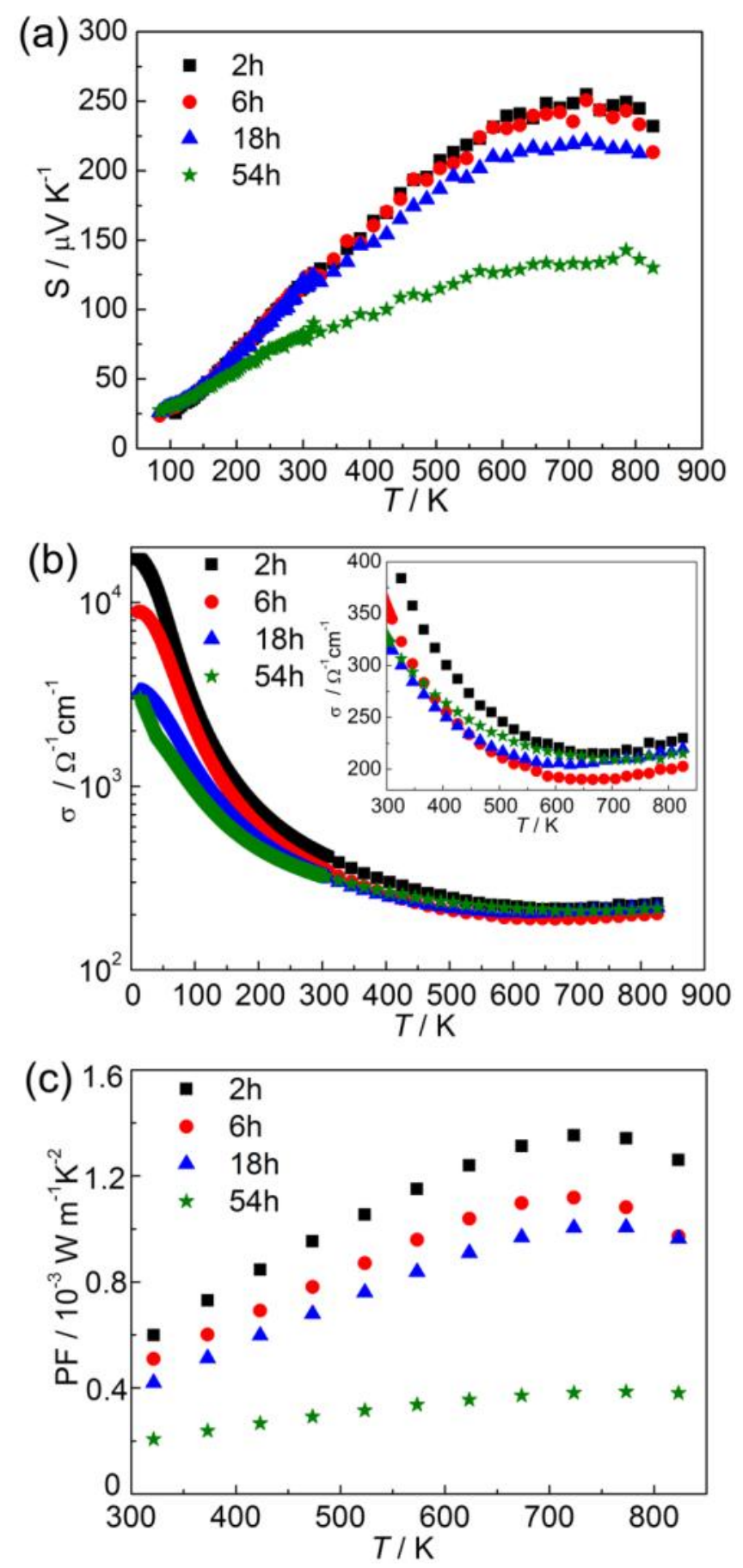

Fig. 5. Temperature dependence of transport properties of various HMS samples with different ball milling time: (a) Seebeck coefficient with 5\% uncertainty, (b) electrical conductivity with 5\% uncertainty, and (c) power factor with $11 \%$ uncertainty. The inset of (b) is the electrical conductivity above $300 \mathrm{~K}$. 

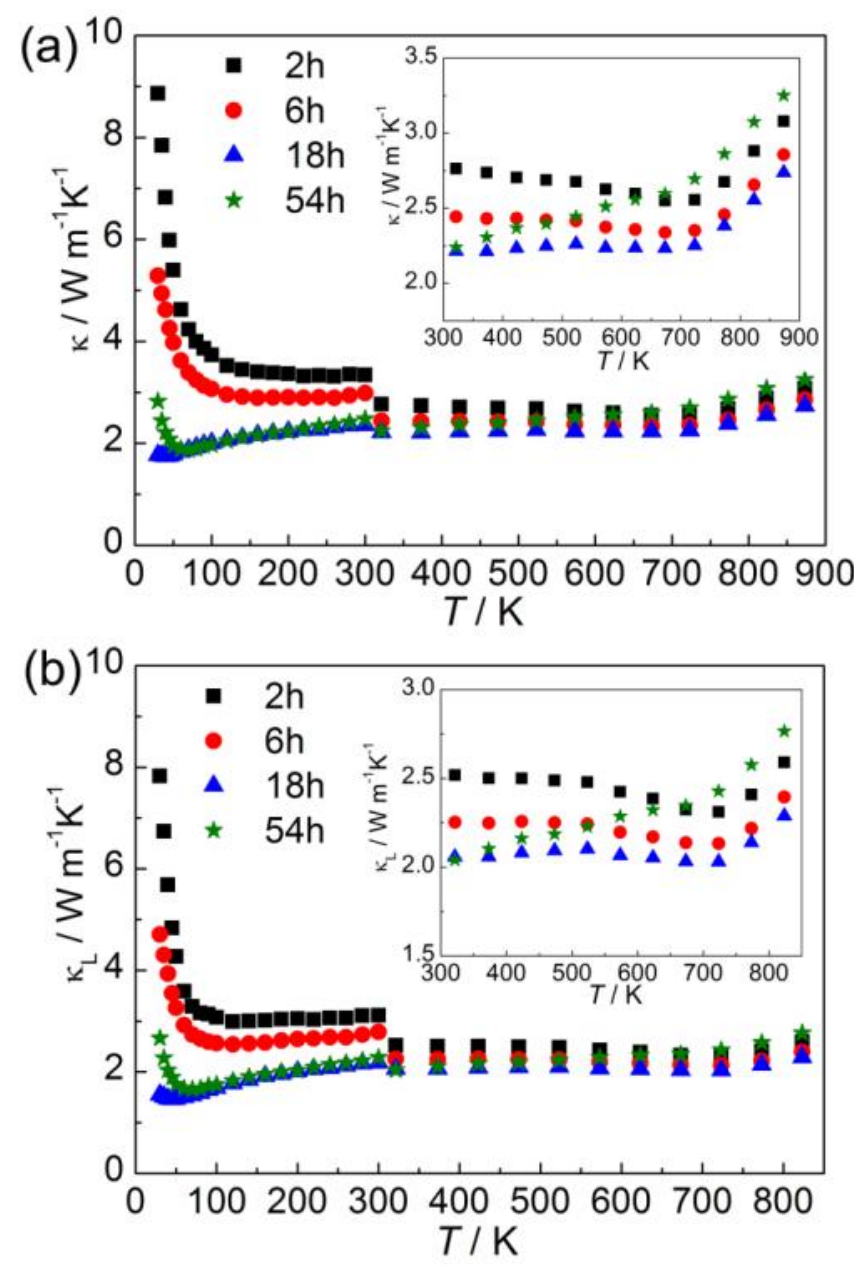

Fig. 6. Temperature dependence of thermal properties of various HMS samples with different ball milling time: (a) total thermal conductivity, and (b) lattice thermal conductivity. The insets are the values above $300 \mathrm{~K}$. The uncertainty for laser flash method and steady-state method are $7 \%$ and $15 \%$, respectively. The discrepancy at $300 \mathrm{~K}$ is due to the measurement errors of these two measurements [18]. 

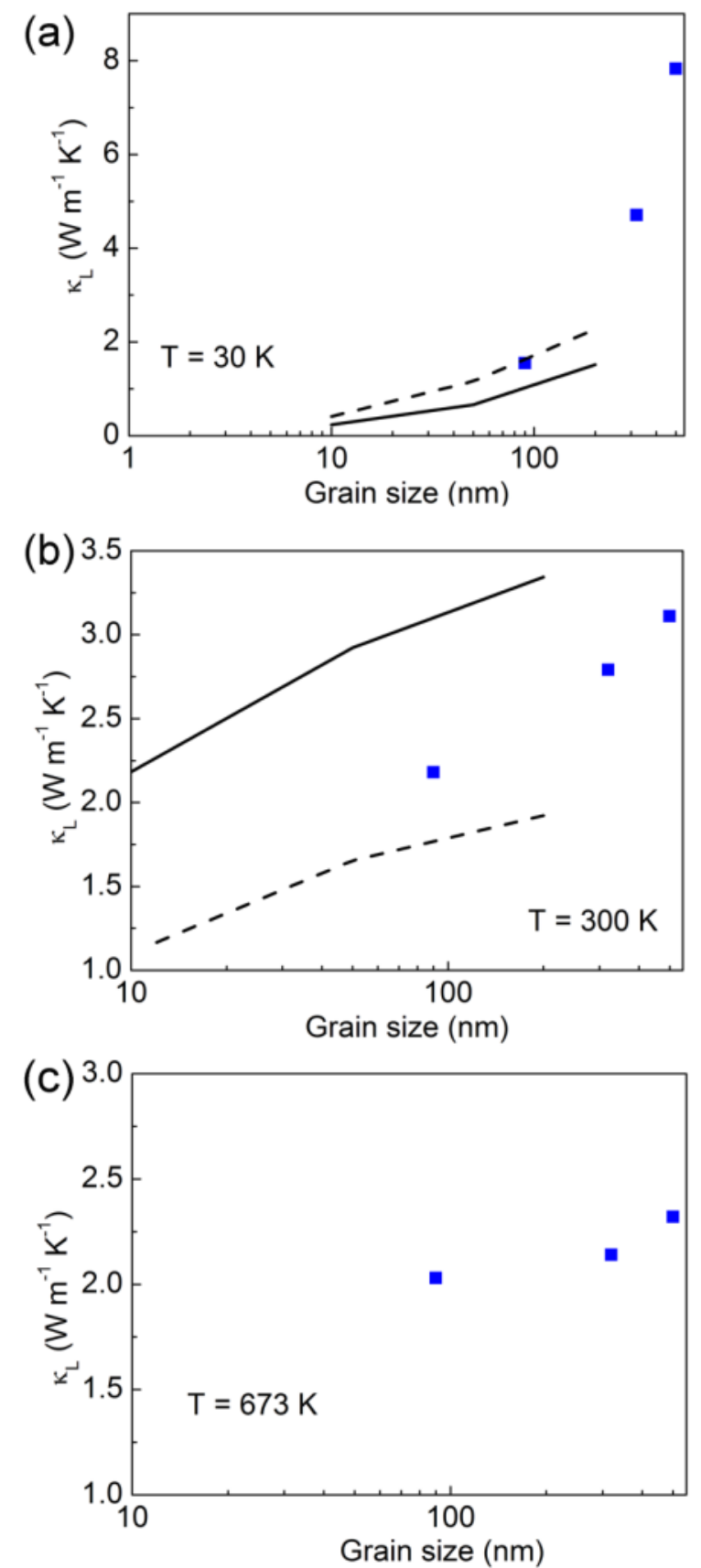

Fig. 7. Grain size dependence of the lattice thermal conductivity for HMS samples at (a) $30 \mathrm{~K}$, (b) $300 \mathrm{~K}$, and (c) $673 \mathrm{~K}$. The solid line and dash line are the calculated lattice thermal conductivity of HMS crystals along the $a$ axis and $c$ axis, respectively, with different boundary scattering MFPs (200, 50, and10 nm) [35]. 


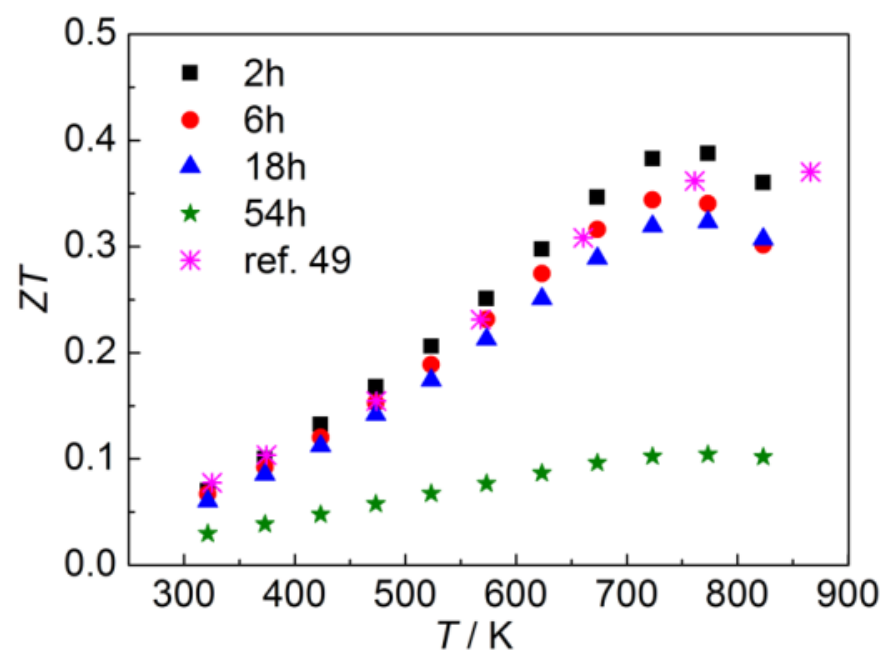

Fig. 8. The dimensionless figure of merit (ZT) of various HMS samples with different ball milling time. The uncertainty of $Z T$ is $13 \%$. Showing for comparison are the data of hot-pressed HMS without ball milling [49].

\section{Tables:}

Table 1. SPS temperature, density, crystallite size and room-temperature electrical transport properties of bulk nanostructured HMS samples after SPS.

\begin{tabular}{llllllllll}
\hline \hline Samples & $\begin{array}{l}\text { BM } \\
\text { time } \\
(\mathrm{h})\end{array}$ & $\begin{array}{l}\text { SPS } \\
\text { temperature } \\
\left({ }^{\circ} \mathrm{C}\right)\end{array}$ & $\begin{array}{l}\text { Density } \\
\left(\mathrm{g} \mathrm{cm}^{-3}\right)\end{array}$ & $\mathrm{L}_{\mathrm{d}}(\mathrm{nm})$ & $\begin{array}{l}\sigma \\
\left(\Omega^{-1} \mathrm{~cm}^{-1}\right)\end{array}$ & $\begin{array}{l}S \\
\left(\mu \mathrm{V} \mathrm{K} \mathrm{K}^{-1}\right)\end{array}$ & $\begin{array}{l}R_{\mathrm{H}} \\
\left(10^{-9} \mathrm{~m}^{3} \mathrm{C}^{-1}\right)\end{array}$ & $\begin{array}{l}p_{\mathrm{H}} \\
\left(10^{21} \mathrm{~cm}^{-3}\right)\end{array}$ & $\begin{array}{l}\mu_{\mathrm{H}} \\
\left(\mathrm{cm}^{2} \mathrm{~V}^{-1} \mathrm{~s}^{-1}\right)\end{array}$ \\
\hline BM2h & 2 & 950 & 4.80 & 500 & 423 & 116 & 5.01 & 1.25 & 2.12 \\
BM6h & 6 & 950 & 4.86 & 320 & 356 & 117 & 5.38 & 1.16 & 1.92 \\
BM18h & 18 & 950 & 4.99 & 90 & 324 & 115 & 4.70 & 1.33 & 3.19 \\
BM54h & 54 & 1000 & 4.41 & 130 & 325 & 83 & 2.00 & 0.64 \\
\hline \hline
\end{tabular}

